application of new methods Dr. Mark described the arrangement of the glucose units in the fibre and of groups of these chains associated as micellar bundles, the length of the chain being about 100-200 glucose residues, in agreement with the value obtained by the chernical methods of the Birmingham school.

The final paper by Mr. W. T. Astbury described the application of X-ray methods in the field of protein chemistry, where again the combination of the results of organic chemistry and physical methods has established the concept of long chain molecules. Protein fibres are built up of polypeptide chains in various states of extension whereas cellulose appears to be laid down in biological structures as fully extended chains. X-ray methods have as yet revealed only two proteins, the fibroin of natural silk and the $\beta$-keratin of stretched hair which are in a fully extended state. Since in natural processes the formation of cellulose and other polysaccharides seems to be effected through the intervention of proteins, it is possible that the protein chains may act as a pattern or framework upon which the sugar units are laid down as a preliminary step to their linking together in polysaccharide chains. It is an interesting point that the chief longitudinal spacings of muscle and of unstretched hair are almost equal to the length of a glucose residue as it occurs in cellulose and the fact that the crossed-cellulose chains of the wall of Valonia ventricosa are laid down according to a definite plan indicates that they have been built on a net-work pattern in the underlying protoplasmic layer.

\title{
Sixth International Congress of Genetics
}

OTWITHSTANDING the small number of
European delegates attending, the International Congress of Genetics held at Cornell University, Ithaca, New York, on August 24-31, was a marked success. This was mainly owing to the large amount of preparatory work undertaken by the Organisation Committee, the Executive Council and the Local Committee. Although many papers were not read in the absence of their authors, the programme was still overcrowded, and the volume of proceedings containing the abstracts of papers and descriptions of exhibits runs to more than four hundred pages. The exhibits alone would have furnished ample material for a busy week. Numerous laboratories in several buildings were devoted to exhibits, in which cytological demonstrations played a prominent part; but they included also living and dried specimens illustrating genetic experiments with fungi, liverworts, mosses, ferns, numerous cereals, economic and other plants, as well as collections of varieties of maize and vegetables and numerous floricultural exhibits. The animal exhibits included Drosophilia and Sciara, Lepidoptera, Orthoptera, bees, aphids, Gammarus, tunicates, echinoderms, molluses, fishes, rats and mice, foxes, pigeons, guinea-pigs, and all the domestic animals, many of the latter as living specimens.

A unique feature of the Congress was the genetic garden (Fig. 1), contributed to by geneticists who had sent seeds from many parts of the world. Here were demonstrated and compared side by side the various forms, hybrids and mutations, of Zea, Enothera, Nicotiana, Primula, Antirrhinum, Pharbitis, Helianthus, Pisum, etc. A special feature arranged by Prof. Emerson was the display of the numerous mutations of Zea in their proper order in the ten chromosomes, as determined by linkage investigations. A chart also showed the loci of more than eighty genes in maize.

The cytological demonstrations were so many that, although a hundred microscopes must have been in use, each exhibit could only be set up for one afternoon. The work on maize chromosomes by the Cornell group was the basis of excited discussions. The great detail of ehromosome structure and behaviour observable in maize is in marked contrast to Drosophila, although here, too, numerous cases of visible translocations were demonstrated.

The morning sessions were devoted to general papers grouped under such topics as the nature and cause of mutations, the interrelations of cytology

$$
\text { No. 3287, Vol. 130] }
$$


On the last day of this crowded week the Congress met at the New York Agricultural Experiment Station, Geneva, where the papers, exhibits and demonstrations related mainly to fruit and vegetable breeding and agricultural bacteriology. This was followed by excursions to New England and Canada, while others dispersed to see the solar eclipse of August 31 .

The Congress must have been a great stimulus to everyone who took part in it, for it served to show that genetics is still a rapidly expanding field, with innumerable practical applications in plant and animal production and also with a widening basis in relation to general biological theory. Many papers showed how technical is becoming the investigation of the Drosophila mutations and the production of mutations in many organisms by X-rays. Perhaps the most general advance indicated since the last Congress in 1927 is the increasing intimacy of relationship demonstrated between chromosome structure and genetic behaviour.

The British delegates included Prof. Ruggles Gates and Prof. F. A. E. Crew, representing the Government, and Dr. R. A. Fisher, Prof. J. B. S. Haldane, Dr. C. C. Hurst, Dr. C. D. Darlington, Dr. Honor Fell and Dr. John Hemmond.

\section{Progress of Aeronautical Research*}

$\mathrm{T}$ HE Aeronautical Research Committee's report of the year's work reflects the general slowing up of all progress consequent upon the reduction of expenditure, in that there has been little new research undertaken, but a good deal of cleaning-up of outstanding detail has been accomplished.

New experimental apparatus has received a good deal of attention. At the National Physical Laboratory the new compressed air tunnel is in working order, and an early obsolete tunnel is being rebuilt with an elliptical cross section and a much higher speed. The R.A.E. has the new vertical free flight tunnel in operation. A modification giving an increase of speed in the new open jet tunnel, and a new high-speed water tank are both practically finished. A $24 \mathrm{ft}$. full scale tunnel is in hand, and should be working by the end of 1933 .

The work on spinning has been collected and collated, and design rules for ease of recovery from, or for complete avoidance of, spinning, have been developed. An interesting sideline in these experiments has been the development of wing-tip parachutes, which can be released at will to act as brakes on the spinning machine. It is suggested that these will reduce the danger when carrying out spinning tests on new type machines, the properties of which in this respect have to be found by actual experiment.

Further research on 'buffeting'-an effect first brought into prominence by the failure of a German D.V.L. aircraft over Meopham-suggests a remedy which in cases appears to clash with that needed to cure spinning. Buffeting can be minimised by keeping the tail plane "in the lowest practicable position in relation to the wings", while for the avoidance of spinning it is necessary to raise the tail plane with respect to the fin and rudder. These contradictory requirements appear to indicate a disadvantage of the low-wing monoplane which has not previously been realised.

The problems of stability and control are adequately met by the development of various forms of slots and interceptors, and as a result of the intensive investigations upon these questions the report suggests that there is now sufficient information in existence to enable designers to achieve a sufficient degree of safety by "correctly shaping and arranging the wings and tail organs without using additional mechanisms on the wings". Similar remarks are made with regard to wing or tail flutter. Airscrew flutter is unfortunately not so completely understood, and further investigations into this are proposed.

* The Aeronautical Research Committee Report for the Year 1931-32. H.M. Stationery Office, 28 , net.
Interference between various adjacent parts of an aeroplane has now been dealt with up to the stage at which it is possible to isolate the various causes and deal with them separately.

A new term, "spoiling drag", has been introduced to indicate an additional drag due to the rotary motion of the airscrew slip stream upon the bodies in it. Suggestions for counteracting it with radial vanes are offered, as the result of wind tunnel experiments.

Attention is directed to the very rapid increase of size of sea-going aircraft during the last few years and to the necessity of keeping pace with this in research, as many new problems due to increase of size are arising. For example, the change of hydrodynamic pressures on hull bottoms during take-off and alighting are giving rise to problems upon the elasticity of the material of the hull plating.

The effect of accelerations imposed upon the aircraft by gusts is now being taken up. Vertical gusts with velocities up to $30 \mathrm{ft}$. per second have been recorded under the edges of certain types of clouds, and there is reason to suppose that even larger ones may be found in stronger winds. Statistical recording accelerometers are being developed for use on aircraft operating over established air routes. On the theoretical side the effect of accelerations on the aerodynamical characteristics of the various parts of a machine is being investigated.

The position with regard to research on aeroengines is peculiar in that it appears that there is little scope for further radical improvement in the present weight of $1.5 \mathrm{lb}$./H.P. with a fuel consumption of $0.5 \mathrm{lb} . /$ B.H.P./H.P. Any further reductions could only be made at the expense of reliability and length of life, but attention to details, such as cooling methods, that allow the engine and aeroplane as a whole to have a better streamline form, will possibly result in an improved performance being obtained for the same power and weight of engine. It is suggested that there is a greater probability of reducing this drag by, say, 20 per cent, than of cutting down either weight or fuel consumption by a similar amount.

In theory, fuel economy is being hindered by unsatisfactory induction pipe distribution in multicylinder engines, and the absence of a control of fuel-air mixture production which automatically adjusts itself to changing air conditions. Direct injection of fuel into the cylinders would remove both of these weaknesses.

Work on compression-ignition engines is progressing both with engines and fuel. It has been decided that the two-stroke direct spray type holds

No. 3287, VoL. 130] 